\title{
Protection of Reinforced Concrete Structures of Waste Water Treatment Reservoirs with Stainless Steel Coating Using Arc Thermal Spraying Technique in Acidified Water
}

\author{
Han-Seung Lee ${ }^{1}$, Jin-Ho Park ${ }^{1}$, Jitendra Kumar Singh ${ }^{1,2, *}$ and Mohamed A. Ismail ${ }^{3}$ \\ 1 Department of Architectural Engineering, Hanyang University, 1271 Sa 3-dong, Sangrok-gu, Ansan 426-791, \\ Korea; ercleehs@hanyang.ac.kr (H.-S.L.); jinho9422@naver.com (J.-H.P.) \\ 2 Department of Chemistry, Indian Institute of Engineering Science and Technology (IIEST), Shibpur, \\ Howrah 711 103, West Bengal, India \\ 3 Department of Civil and Construction Engineering, Faculty of Engineering and Science, \\ Curtin University Sarawak, CDT 250, Miri 98009, Sarawak, Malaysia; m.abdelkader@curtin.edu.my \\ * Correspondence: jk200386@hanyang.ac.kr; Tel.: +82-31-400-5181
}

Academic Editor: Reza Montazami

Received: 20 April 2016; Accepted: 29 August 2016; Published: 3 September 2016

\begin{abstract}
Waste water treatment reservoirs are contaminated with many hazardous chemicals and acids. Reservoirs typically comprise concrete and reinforcement steel bars, and the main elements responsible for their deterioration are hazardous chemicals, acids, and ozone. Currently, a variety of techniques are being used to protect reservoirs from exposure to these elements. The most widely used techniques are stainless steel plating and polymeric coating. In this study, a technique known as arc thermal spraying was used. It is a more convenient and economical method for protecting both concrete and reinforcement steel bar from deterioration in waste water treatment reservoirs. In this study, 316L stainless steel coating was applied to a concrete surface, and different electrochemical experiments were performed to evaluate the performance of coatings in different acidic $\mathrm{pH}$ solutions. The coating generated from the arc thermal spraying process significantly protected the concrete surface from corrosion in acidic $\mathrm{pH}$ solutions, owing to the formation of a double layer capacitance-a mixture of $\mathrm{Cr}^{3+}$ enriched with $\mathrm{Cr}_{2} \mathrm{O}_{3}$ and $\mathrm{Cr}$-hydroxide in inner and $\mathrm{Fe}^{3+}$ oxide on the outer layer of the coating. The formation of this passive film is defective owing to the non-homogeneous 316L stainless steel coating surface. In the $\mathrm{pH} 5$ solution, the growth of a passive film is adequate due to the presence of un-dissociated water molecules in the aqueous sulfuric acid solution. The coated surface is sealed with alkyl epoxide, which acts as a barrier against the penetration of acidic solutions. This coating exhibits higher impedance values among the three studied acidic $\mathrm{pH}$ solutions.
\end{abstract}

Keywords: acid; stainless steel; concrete; coating; electrochemical impedance spectroscopy; potentiodynamic

\section{Introduction}

Waste water contains various types of microbes, including sulfur-reducing bacteria, hazardous materials (i.e., $\mathrm{Pb}, \mathrm{As}, \mathrm{Sn}, \mathrm{Cd}$ ), and acidic elements, all of which are harmful to living organisms. The waste water can be made potable after treatment. However, owing to the initial presence of these acidic and harmful elements in the wastewater, concrete waste water treatment reservoirs receive direct exposure to them [1]. Concrete is a porous material, which means that aggressive species of waste water are able to diffuse into and out of it, exposing the surrounding ground to contamination [2,3]. Hazardous waste water chemicals affect the quality of concrete and are responsible for its deterioration, 
as well as the deterioration of the reinforcement steel bars embedded within, after a certain period of time [4]. This deterioration is the result of carbonation, exposure to chloride ions, and acidification.

Other factors that affect the quality of waste water treatment reservoirs are ozone and activated granular carbon. These chemicals are used for the purification of water in advanced water treatment plants. These chemicals can cause cracking, fading, and spalling of concrete during short periods of exposure [5]. Owing to the cracking and spalling of the reservoir concrete, the reinforcement steel bars start to corrode. Besides ozone and activated carbon, other acidic components are present in waste water. Examples include $\mathrm{H}_{2} \mathrm{~S}$ and $\mathrm{H}_{2} \mathrm{CO}_{3}$, which reduce the $\mathrm{pH}$ of water from neutral ( $\mathrm{pH}$ of 7) to acidic ( $\mathrm{pH}$ of 4). Ozone causes the color of concrete to fade after six years of exposure [5]. Finally, activated carbon is adsorbed on steel surfaces through the pores of the concrete and can cause severe corrosion of the embedded steel bars.

When concrete is subjected to harsh environments for a prolonged period of time, it begins to deteriorate. There are many recommended methods for protecting concrete in waste water reservoirs, including polymeric coatings $[6,7]$ and stainless steel plating $[8,9]$. The polymeric coating has several drawbacks, including color fading and adhesion due to direct exposure to ozone in waste water treatment reservoir. The thermal contraction and expansion coefficients of polymers and concrete are different, which causes the detachment of the polymeric coating from concrete and can lead to spalling after a period of time. The stainless steel plates are used with grouting and anchoring on the outer surface of concrete. However, this process is not economical, and researchers do not recommend its use. Researchers recommend a stainless steel coating on the outer surface of the concrete of waste water treatment reservoirs. Based on the drawbacks of the protective schemes listed above, it was decided to apply the stainless steel coating using the arc thermal spraying process, as it is convenient, environmentally friendly, economical, and easy to apply.

The arc thermal spray coating can be applied on a clean newly erected or corroded surface. During the arc thermal spraying process, twin wires are used for coating and an electric arc melts the tips of the wires. After arcing, the wires melt and are atomized by hot air, which impinges on the target (substrate) surface. The melted metal droplets adhere onto the substrates and are cooled at room temperature, resulting in the formation of a thick coating [10]. Owing to the high spraying speed and the sudden cooling of the melted metal droplets on the substrate surface, macro pores/defects are formed [11-15] in the coating.

Waste water treatment reservoirs contain many aggressive species of chemicals and microbes, which leads to the corrosion of reinforced concrete. Therefore, it was decided to protect the reinforced concrete from exposure to these harmful elements using a 316L stainless steel coating applied by arc thermal spraying process. A literature review revealed that research had not yet been performed on the protection of concrete using a 316L stainless steel coating in different acidic $\mathrm{pH}$ solutions.

\section{Experimental Procedure}

\subsection{Process of Coating}

The stainless steel coating was applied on the concrete surface using the arc thermal spraying process. The composition of the $1.6 \mathrm{~mm}$ wire is shown in Table 1 . The wires are mainly comprised of $\mathrm{Mn}, \mathrm{Cr}, \mathrm{Ni}, \mathrm{Mo}$, and $\mathrm{Fe}$, which resembles the composition of $316 \mathrm{~L}$ stainless steel. The thickness of the coating was measured by an Elcometer 456 dry film thickness gauge (Shinagawa-ku, Tokyo, Japan) at different locations on the concrete-approximately $200 \mu \mathrm{m}( \pm 5 \mu \mathrm{m})$. Figure 1 shows that the arc thermal spraying process using the 316 L stainless steel coating was applied on the concrete surface with a circular slit of hot and compressed air [16-18]. The melted metal diffused and cooled at room temperature and pores were formed in the coating. The spraying of $316 \mathrm{~L}$ stainless steel on the concrete surface was accomplished by keeping the sample $20 \mathrm{~cm}$ away from the spray gun at an air pressure of 6 bars. The spraying voltage and current were maintained at approximately $30 \mathrm{~V}$ and $200 \mathrm{~mA}$, respectively [19-22]. 
Table 1. Composition of 316L stainless steel wires used in coating.

\begin{tabular}{cccccccccc}
\hline \multicolumn{10}{c}{ Elements (wt \%) } \\
\hline $\mathbf{C}$ & $\mathbf{M n}$ & $\mathbf{S i}$ & $\mathbf{C r}$ & $\mathbf{N i}$ & $\mathbf{M o}$ & $\mathbf{P}$ & $\mathbf{S}$ & $\mathbf{N}$ & $\mathbf{F e}$ \\
\hline 0.03 & 1.940 & 0.700 & 16.790 & 9.600 & 1.800 & 0.040 & 0.025 & 0.010 & balance \\
\hline
\end{tabular}

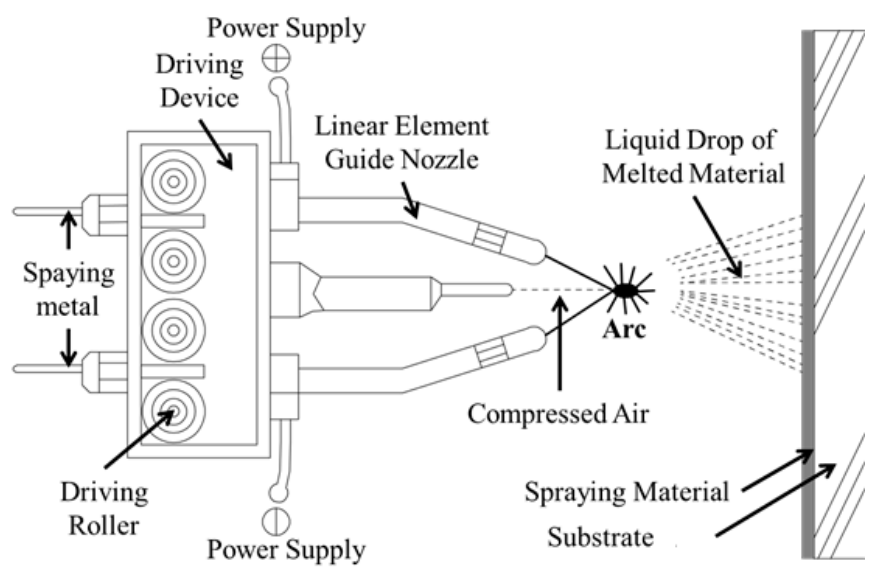

Figure 1. Schematic of the arc thermal spraying process.

After application of the coating on the concrete surface, the adhesion of the coating was measured according to the ASTM D4541 test method [23]. In this process, a $40 \mathrm{~mm} \times 40 \mathrm{~mm}$ section of the coating substrate was taken for an adhesion test.

\subsection{Electrochemical Experiments}

Electrochemical experiments were carried out on the applied coating and the 316L stainless steel plate. After coating, different processes were employed to smooth the roughened surface of the sprayed coatings. The sprayed coating surface was abraded with $600 \mu \mathrm{m}$ emery paper to smooth the surface, and alkyl epoxide was used to fill the pores/defects in the sprayed coating.

To perform the electrochemical experiments, the solution was prepared in double distilled water by adding a few drops of $0.5 \mathrm{M} \mathrm{H}_{2} \mathrm{SO}_{4}$ to reduce the $\mathrm{pH}$ below 7 at $25^{\circ} \mathrm{C}$. Three different $\mathrm{pH}$ solutions were chosen for the experiments: $\mathrm{pH} 6, \mathrm{pH}$, and $\mathrm{pH} 4$. These experiments were performed by three electrode systems (Figure 2), where the coating acted as the working electrode (WE), the platinum wire acted as the counter electrode (CE), and the silver-silver chloride acted as the reference electrode (RE). The WE was soldered with copper wire to the coating. To ascertain a proper electrical connection, a multi-meter was used to measure the resistance because the back side of coating substrate was concrete, which is non-conducting in nature. The area of the working electrode was $0.78 \mathrm{~cm}^{2}$, and it was fixed for all the samples.

The electrochemical impedance spectroscopy (EIS) experiments were carried out by changing the frequency of a $10 \mathrm{mV}$ sinusoidal voltage from $100 \mathrm{kHz}$ to $0.01 \mathrm{~Hz}$. DC polarization experiments were performed from $-0.4 \mathrm{~V}$ to $+0.8 \mathrm{~V}$ vs. open circuit potential at $1 \mathrm{mV} / \mathrm{s}$ scan rate. The potentiostat was a VersaSTAT (Princeton Applied Research, Oak Ridge, TN, USA), and the data analysis was carried out using the Metrohm Autolab Nova 1.10 software. The 316L stainless steel plate was polished to remove oxides from the surface prior to starting any electrochemical experiments. All electrochemical experiments were carried out in triplicate at room temperature $\left(27 \pm 1^{\circ} \mathrm{C}\right)$ to generate reproducible data. 


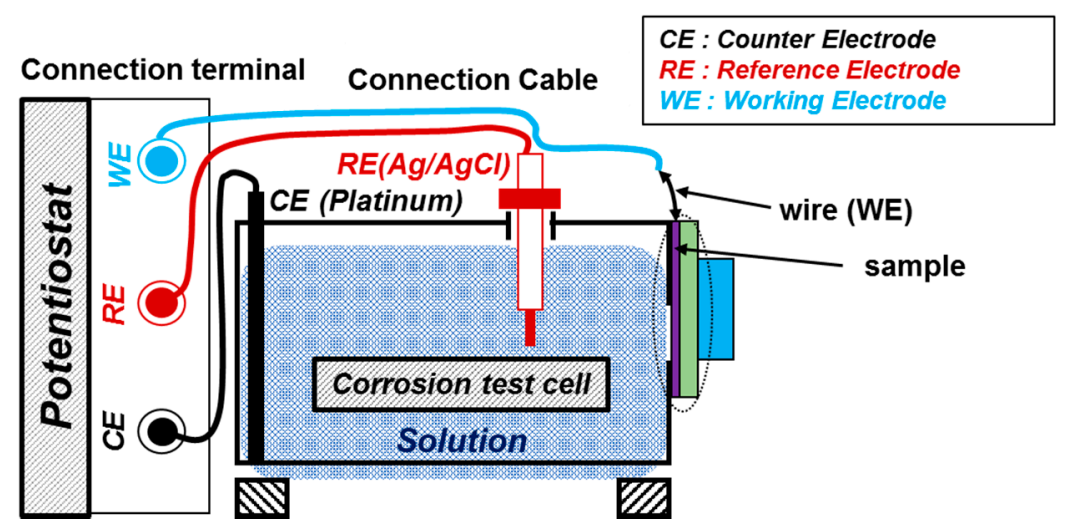

Figure 2. Schematic of the electrochemical setup.

\subsection{Characterization of Coating}

The morphology of the coating, plate, and concrete were determined using a scanning electron microscope (SEM, Philips XL 30, North Billerica, MA, USA) operated at $15 \mathrm{kV}$. Prior to taking the images of coatings using an SEM, they were coated with platinum to increase their conductivity and avoid a charging effect.

\section{Results}

\subsection{Morphology of Coatings, Plate, and Concrete Surface}

The SEM images of the top surface of the coating, the 316L stainless steel plate, and the concrete surface are shown in Figure 3. The 316L stainless steel sprayed surface is rough, with evidence of defects/pores and unevenness (Figure 3a). This surface facilitates the ingress of aggressive ions, gases, and moisture from the atmosphere, which can later cause deterioration of the coating. To smooth out the sprayed surface, the coatings were polished with emery paper and sprayed with alkyl epoxide to fill the pores/defects. The polished (abraded) and epoxide coated (sealed) surfaces are presented in Figure $3 b, c$, respectively. The abraded (Figure 3b) surface is slightly smoother than the sprayed surface, owing to the process of polishing with emery paper. The sealed surface (Figure 3c) filled the pores of the coating by alkyl epoxide and worked as a barrier against the penetration of aggressive ions and acidic gases towards the substrate. Figure 3d shows the top surface of the polished 316L stainless steel plate, which is uniform with minimum defects or scratches. The ordinary Portland cement (OPC) concrete morphology exhibited macro- and micro-sized pores connected with circular and elongated holes (Figure 3e). The concrete structure was porous and allowed the ingress of water and other aggressive molecules in and out of the surface.

The adhesion test on the coating on the concrete surface was measured; the respective standard deviations are presented in Table 2 . The adhesion test on the coating was conducted for four samples and the average was calculated. From Table 2, it can be seen that the sprayed and abraded coatings have almost the same average adhesion results, with values of $3.39 \mathrm{MPa}$ and $3.31 \mathrm{MPa}$, respectively. The adhesion of the sealed surface with the alkyl epoxide coating was $4.06 \mathrm{MPa}$, which was greater than the sprayed and abraded coatings. This result suggests that the adhesion of alkyl epoxide with a coating substrate was more pronounced. The maximum standard deviation was observed in the sprayed coating substrate $(0.21 \mathrm{MPa})$ while the lowest standard deviation was observed in the sealed surface $(0.06 \mathrm{MPa})$. The pull-off adhesion tester was used on the coating surface by increasing the load on it; the adhesion was measured at certain applied loads when the coating detached from the surface. The adhesion of the coating was lower than what is recommended in ASTM D4541 [23], which can be attributed to the selection of a larger coating surface area $\left(16 \mathrm{~cm}^{2}\right)$. 

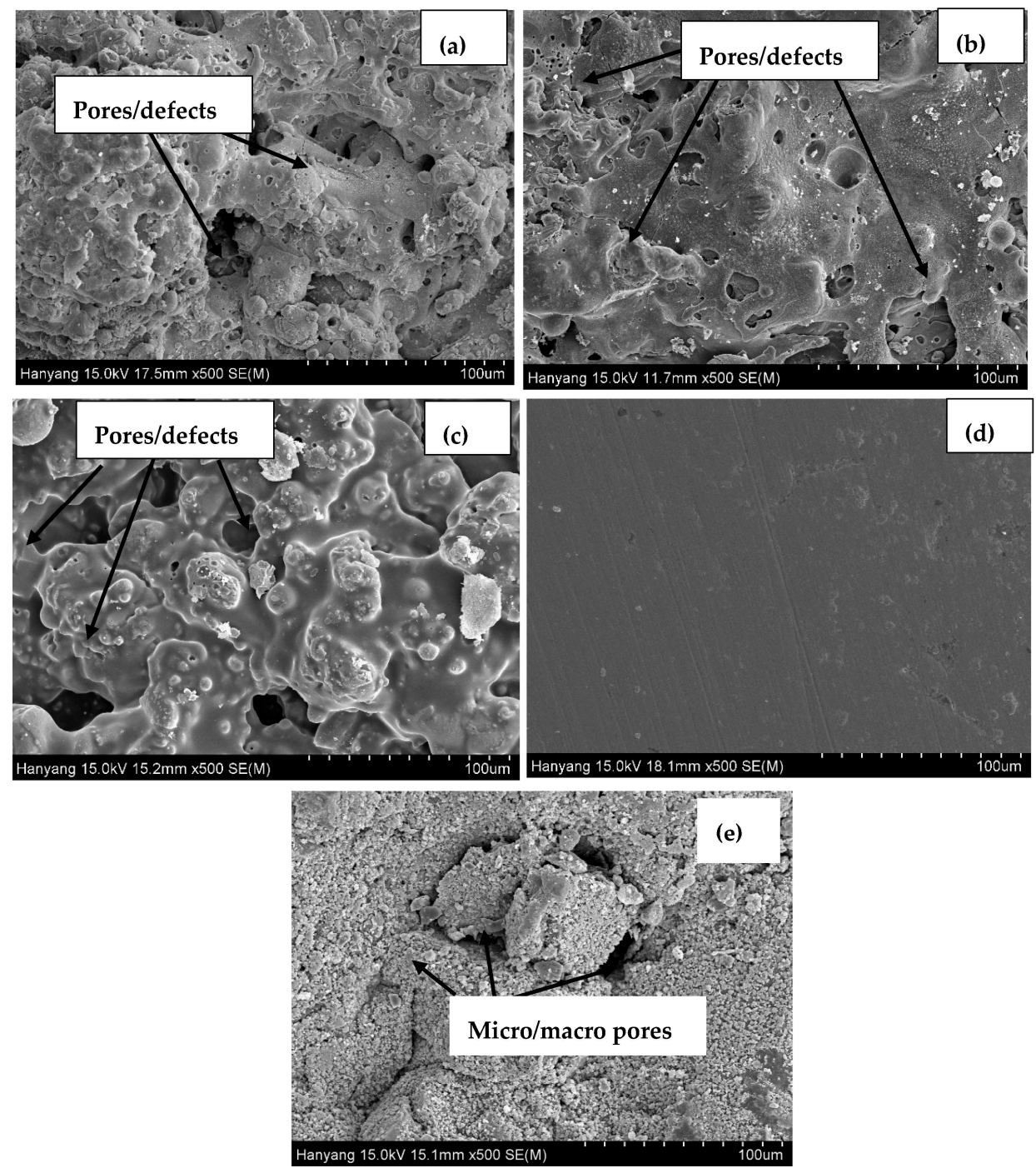

Figure 3. SEM images of 316L stainless steel coating (a) sprayed; (b) abraded; and (c) sealed; (d) stainless steel plate; and (e) OPC concrete (without coating).

Table 2. Bond adhesion test results of the 316L stainless steel coating on the concrete surface applied using the arc thermal spraying process.

\begin{tabular}{|c|c|c|c|c|c|c|}
\hline \multirow{2}{*}{ Sample Details } & \multicolumn{4}{|c|}{ Bond Strength (MPa) } & \multirow{2}{*}{ Average (MPa) } & \multirow{2}{*}{ Standard Deviation (MPa } \\
\hline & 1 & 2 & 3 & 4 & & \\
\hline Sprayed & 3.57 & 3.56 & 3.29 & 3.14 & 3.39 & 0.21 \\
\hline Abraded & 3.33 & 3.22 & 3.19 & 3.49 & 3.31 & 0.14 \\
\hline Sealed & 4.12 & 4.09 & 4.02 & 3.99 & 4.06 & 0.06 \\
\hline
\end{tabular}

\subsection{Electrochemical Experiments for Different $p H$ Solutions}

\subsubsection{EIS Experiments for Different $\mathrm{pH}$ Solutions}

The EIS study is an established and powerful technique used to study the phenomena occurring at the metal/solution interface at open circuit potential [24]. The EIS experiments on the top surface of the coatings, and the 316L stainless steel plate were carried out in solutions of different $\mathrm{pH}$ values and are shown in Figures 4-6. In most of the EIS plots, it can be seen that the graphs are scattered owing to the low conductivity of the solutions and the capacitive properties of passive layers in intermediate 
frequency ranges. These passive layers contain double layers, a mixed $\mathrm{Cr}^{3+}$ enriched with $\mathrm{Cr}_{2} \mathrm{O}_{3}$ layer, $\mathrm{Cr}$-hydroxide in the inner layer, and $\mathrm{Fe}^{3+}$ oxide in the outer layer, [25]. The scattered graph in the intermediate frequency range is due to the defective passive film and the high capacitive response. This type of plot was also observed by other researchers [24-27].

The Nyquist plots for the 316 stainless steel coating and plate tested in the $\mathrm{pH} 6$ solution are shown in Figure 4a. A typical Nyquist plot is observed for the sealed and plate samples. As the dimensions of a Nyquist plot are increased, the resistive properties of the samples also increase. This observation is noted in the sealed surface of the coating in the $\mathrm{pH} 6$ solution. The Nyquist plots for the sprayed, abraded, and plate surface samples can be shown in the inset of Figure 4a because their dimensions are very small and are suppressed owing to the sealed coating plot. The scattered data results are observed in this $\mathrm{pH}$ solution owing to the reduced conductivity of the solution and the capacitive properties of passive films. The tendency of formation of the passive film is the same for all coatings and is seen in the Nyquist plots.

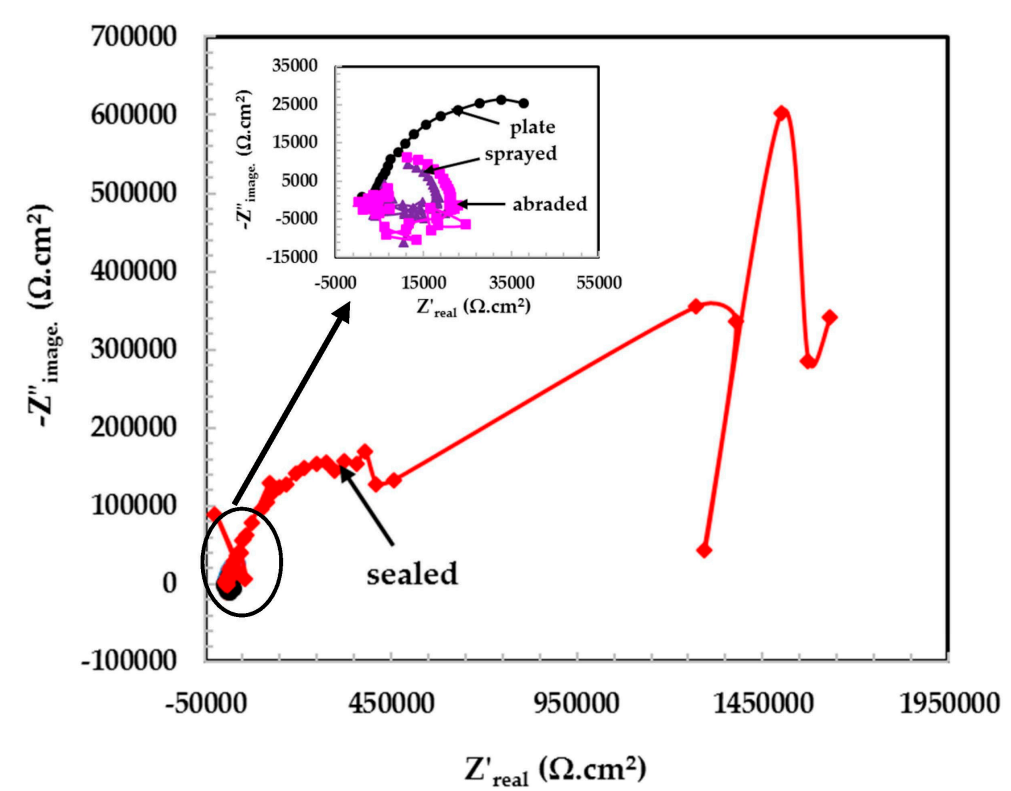

(a)

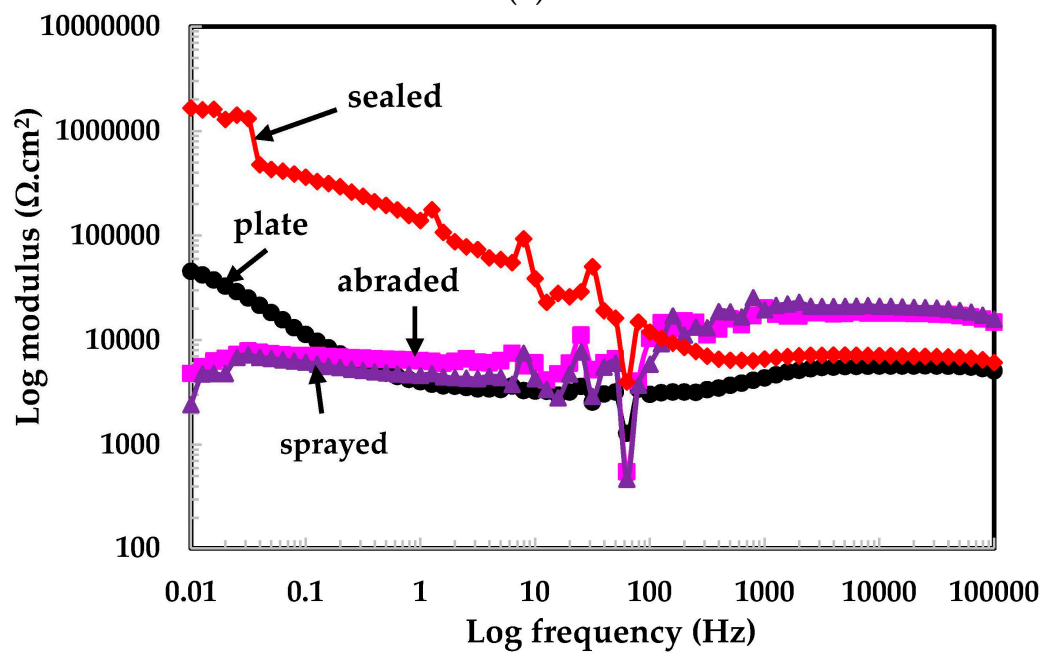

(b)

Figure 4. Cont. 


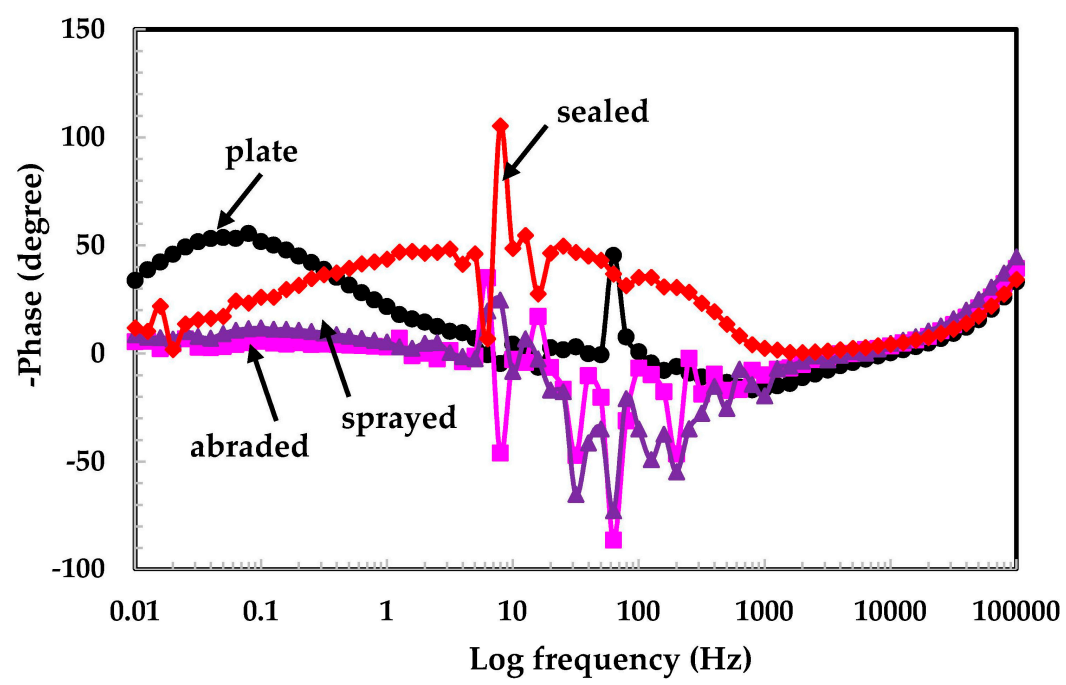

(c)

Figure 4. (a) Nyquist plots of $316 \mathrm{~L}$ stainless steel coating applied by a spraying in $\mathrm{pH}=6$; (b) $\log$ modulus-frequency Bode plots of the 316L stainless steel coating applied by arc thermal spraying in $\mathrm{pH}=6$; (c) phase-frequency Bode plots of 316L stainless steel coating applied by the arc thermal spraying process at $\mathrm{pH}=6$.

The EIS graphs are plotted from $100 \mathrm{kHz}$ to $0.01 \mathrm{~Hz}$ and the total impedance values are measured at the lowest studied frequency (i.e., $0.01 \mathrm{~Hz}$ ). Figure $4 \mathrm{~b}$ shows the log modulus-frequency Bode plots of coatings exposed in the pH 6 solution. From Figure 4b, it is observed that the sealed surface of the coating exhibited the highest impedance values of all the coatings because it works as a barrier against the penetration of the solution. However, the low impedance for the $316 \mathrm{~L}$ stainless steel plate is due to the oxide layer that is removed because of the polishing surface. Therefore, the surface became bare and began to deteriorate when it came into contact with the solution. The solution resistance $\left(R_{s}\right)$ at the highest frequency considered $(100 \mathrm{kHz})$ is too high because the conductivity of distilled water is lower at $25{ }^{\circ} \mathrm{C}$, which causes additional resistance to electrochemical reaction. There is no considerable difference observed in the impedance values of the sprayed and abraded surface of coatings and they are almost the same as $R_{s}$. This may be due to the very low reactivity of the solution with the coatings.

The phase-frequency Bode plots in the $\mathrm{pH} 6$ solution are shown in Figure 4c. The sealed and plate surfaces exhibiting two maxima in different frequency ranges indicate the formation of a capacitance on the corroding interface in middle frequency and passive film formation at lower studied frequency, while the abraded and sprayed surfaces show only one-time constant attributed deterioration property of coating at lower frequency with low angle shift. Figure 4c shows the resistive properties in high frequency, the capacitance at middle frequency, and the broad peak in the low frequency region, which indicate the formation of a passive film [28]. The plate surface sample maxima are shifting about $-50^{\circ}$ at a lower frequency, which is attributed to the formation and growth of the passive film [29].

The Nyquist plots for the samples exposed in the $\mathrm{pH} 5$ solution are shown in Figure $5 \mathrm{a}$. The dimensions of the Nyquist plots for the sealed samples are the highest, which is attributed to the formation of a highly stable passive film and un-dissociated water molecules in the $\mathrm{pH} 5$ solution. At the low frequency the plots are scattered, which may be due to the high resistance of the passive film. This passive film might be non-conducting in nature and cause more resistance to the deterioration of the surface. Another reason may be the non-conducting nature of alkyl epoxide. The Nyquist plots for the other samples are shown in the inset of Figure 5a. The 316L stainless steel plate surface exhibited a larger semi-circle loop than the abraded and sprayed surfaces, which is attributed to the fact that they are more resistant to corrosion in a $\mathrm{pH} 5$ solution than abraded and 
sprayed samples. Other coating surfaces, i.e., abraded and sprayed samples that exhibit more defects, are susceptible to corrosion in a solution of $\mathrm{pH} 5$.

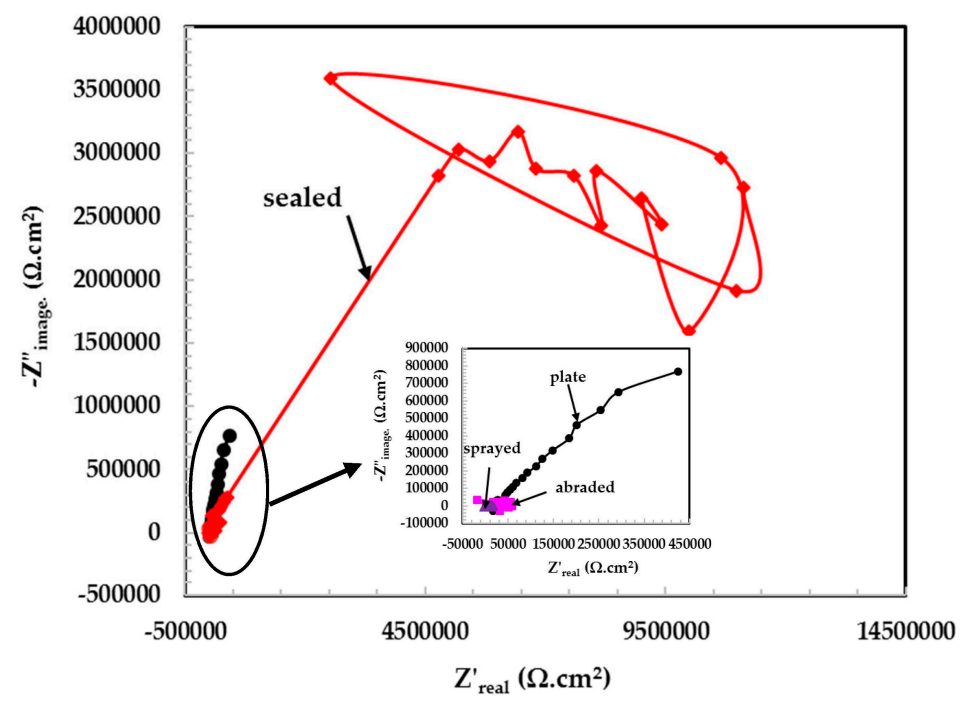

(a)

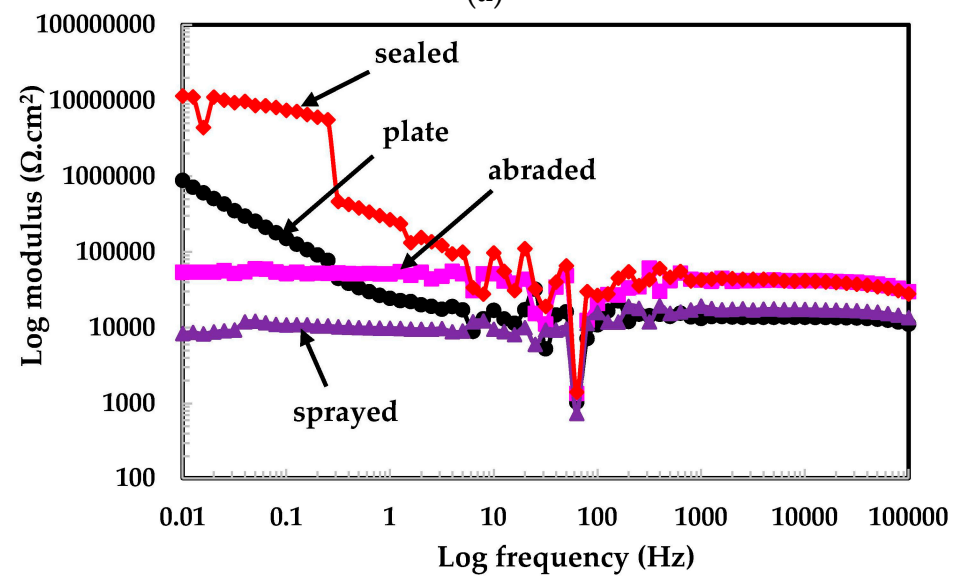

(b)

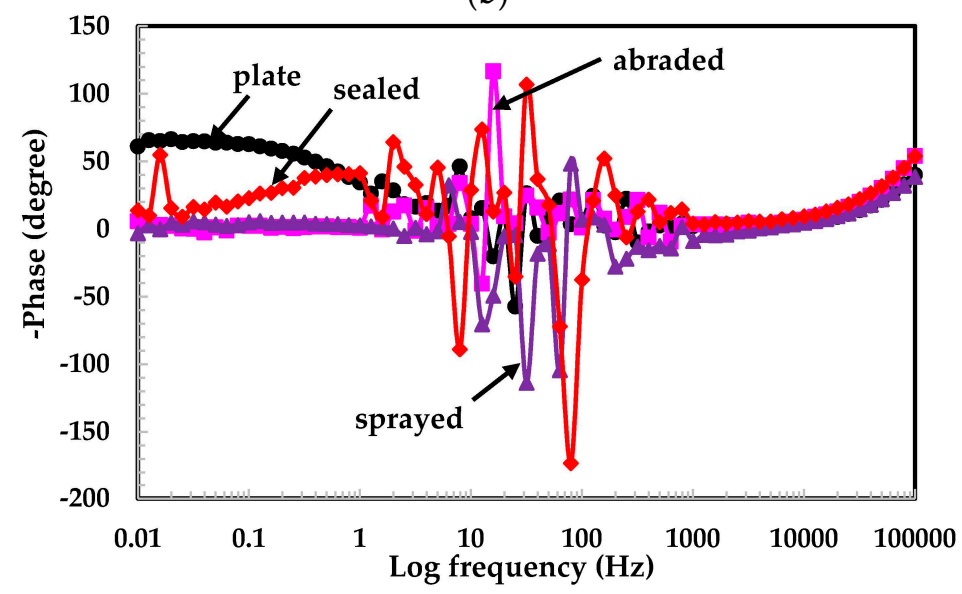

(c)

Figure 5. (a) Nyquist plots of 316L stainless steel coating applied by arc thermal spray process at $\mathrm{pH}=5$; (b) $\log$ modulus-frequency Bode plots of 316L stainless steel coating applied by arc thermal spray process at $\mathrm{pH}=5$; (c) phase-frequency Bode plots of 316L stainless steel coating applied by arc thermal spray process at $\mathrm{pH}=5$. 
The log modulus-frequency Bode plots in the $\mathrm{pH} 5$ solution are shown in Figure $5 \mathrm{~b}$. It was observed that the total impedance values for all coatings are very high and pronounced to provide a higher degree of protection. It is possible that in this particular $\mathrm{pH}$ solution, the un-dissociated water molecules exist in a high concentration and thus passivate the surface significantly. Other researchers had also discovered that the solution containing aqueous $\mathrm{H}_{2} \mathrm{SO}_{4}$ contains un-dissociated water molecules that passivate the stainless steel surface significantly [30]. From the log modulus-frequency plots, (Figure 5b) it can be seen that the sealed surface exhibits a higher impedance value than the plate, followed by the abraded and sprayed coating.

The phase-frequency Bode plots (Figure 5c) show the higher capacitive property of the film that formed on the corroding interface [31]. The sealed coating and 316L stainless steel plate show broad peaks from the mid to the lower frequency range, which is attributed to passivation and response to capacitive properties. The passive film formed in this $\mathrm{pH}$ solution is compact, adherent, and non-hydrated [32]. It may be that more $\mathrm{Fe}^{3+}$ and $\mathrm{Cr}^{3+}$ ions exist in this passive film. The presence of these ions in the film is attributed to its enhanced resistance to corrosion.

The Nyquist plots of the samples in the $\mathrm{pH} 4$ solution are shown in Figure 6a. It can be seen that the dimensions of the semi-circular loop for all the studied samples are smaller than in the other $\mathrm{pH}$ solutions. It is possible that in such acidic $\mathrm{pH}$ solutions, the coating started to deteriorate, resulting in a smaller semi-circular loop. This $\mathrm{pH}$ solution is, therefore, more susceptible to corrosion, as all the samples exhibited deterioration. There is an inductive loop found in the plate sample due to the diffusion of corrosive products from the surface.

As the $\mathrm{pH}$ decreases, the total impedance values are decreased owing to the reduction in $\mathrm{pH}$ of the solution. The synergistic effect was caused by $\mathrm{H}^{+}$and $\mathrm{SO}_{4}{ }^{2-}$ ions, which enhances the corrosion of the corroding interface. This type of observation is found from Figure $6 \mathrm{~b}$ in the lowest studied $\mathrm{pH}$ solution. It is obvious that the deterioration/corrosion of a metallic surface increases at fixed instances and depends on the material, $\mathrm{pH}$ of the solution, solution content, and temperature [29,33]. A considerable decrease in impedance value is observed from Figure $6 \mathrm{~b}$, and it is the reduction in the $\mathrm{pH}$ of the solution that causes the deterioration of the coatings. The results show that the sealed surface performed better than the plate, followed by the abraded and sprayed surfaces.

The phase angle shifted towards a lower frequency with a decrease in angle. This may be attributed to the increase in the anodic surface area of the corroding interface and a decrease in the impedance value (Figure 6c). It is observed that all coatings in the $\mathrm{pH} 4$ solution exhibit two maxima at the lower and higher frequencies. At lower frequency, this phenomenon is attributed to corrosion. At higher frequency, corrosion products blocked the pores/defects of the coating and filled the pits [34]. The phase angle for the sealed surface is shifted towards $-75^{\circ}$ to $-80^{\circ}$ (Figure $6 \mathrm{c}$ ) at lower frequency, and it is confirmed that these surfaces have less anodic surface area than the plate surface, followed by the abraded and sprayed surfaces. The lesser anodic surface area for the sealed surface may be due to alkyl epoxide working as barrier against the penetration of the solution into the coating substrate. The phase angle shifted towards higher frequency for the sprayed and abraded samples due to the deposition of corrosion products on the coating surface at approximately $20^{\circ}$ to $25^{\circ}$. The $316 \mathrm{~L}$ stainless steel plate surface exhibiting approximately $12^{\circ}$ at lower frequency might be due to initial corrosion in such a low $\mathrm{pH}$ solution. It can be seen from Figure $3 \mathrm{~d}$ that there are fewer defects/scratches present on the plate surface than on other coatings. Therefore, the corrosion products' deposition was less on 316L stainless steel plate surface than on abraded and sprayed surfaces. 


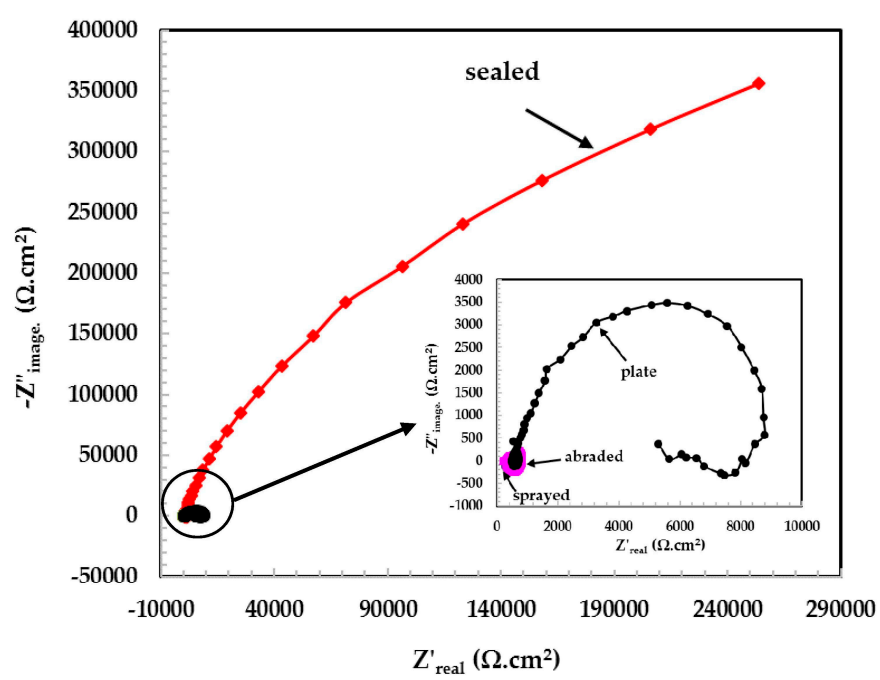

(a)

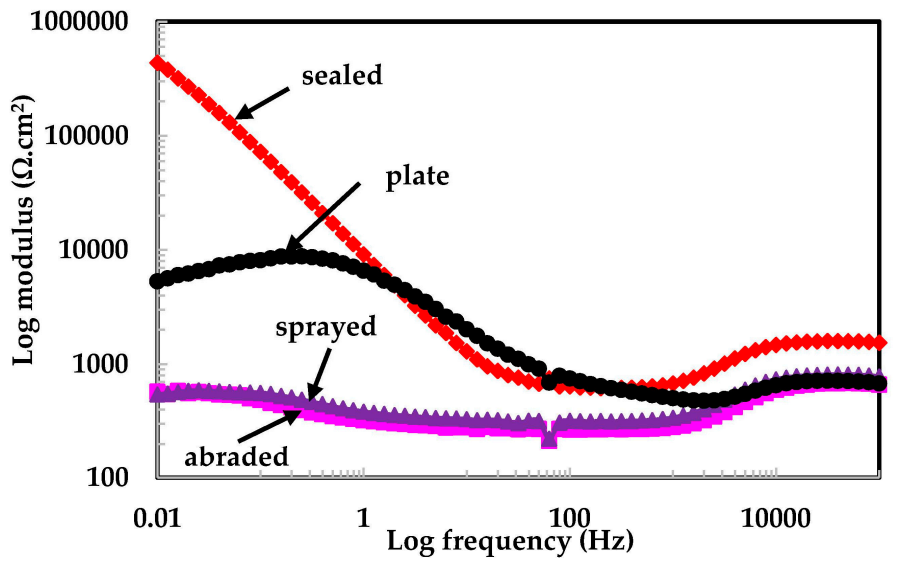

(b)

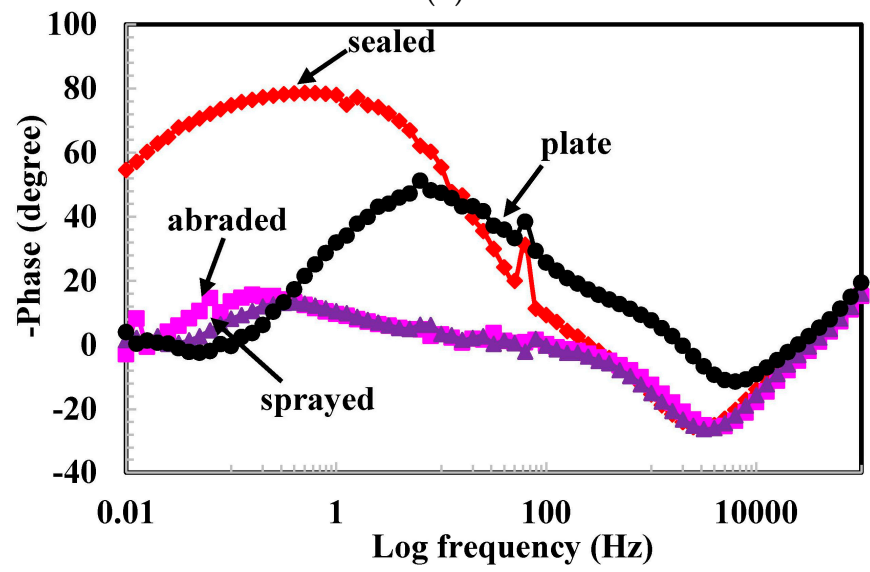

(c)

Figure 6. (a) Nyquist plots of 316L stainless steel coating applied by arc thermal spraying at $\mathrm{pH}=4$; (b) $\log$ modulus-frequency Bode plots of 316L stainless steel coating applied by arc thermal spraying at $\mathrm{pH}=4$; (c) phase-frequency Bode plots of 316L stainless steel coating applied by arc thermal spraying at $\mathrm{pH}=4$.

The electrical equivalent circuit (EEC) for tested samples in different $\mathrm{pH}$ solutions is presented in Figure 7. Figure 7a shows the EEC for sprayed, abraded, sealed, and plate surfaces at pH 6, as well as at $\mathrm{pH} 5$ and $\mathrm{pH} 4$ for sprayed and abraded samples. The polarization resistance $\left(R_{\text {pore }}\right)$ and constant phase element for coating $\left(C P E_{c}\right)$ are parallel to each other. The sealed samples exposed in pH 5 and 
$\mathrm{pH} 4$ solutions and their EEC are shown in Figure $7 \mathrm{~b}$. The sealed surface coating exposed to $\mathrm{pH} 4$ and pH 5 exhibited another constant phase element $\left(C P E_{d l}\right)$ and resistance $\left(R_{d l}\right)$ for double layer due to the formation of the passive film. The $R_{d l}$ and $C P E_{d l}$ in parallel are associated with $R_{\text {pore }}$ in series. Warburg impedance $(\mathrm{W})$ is observed in a $\mathrm{pH} 5$ solution for plate samples owing to the diffusion of ions from the surface and caused resistance (Figure 7c). The inductive loop is observed in the Nyquist as well as in the phase-frequency Bode plot of the 316 stainless steel plate sample exposed to a $\mathrm{pH} 4$ solution (Figure 7d).
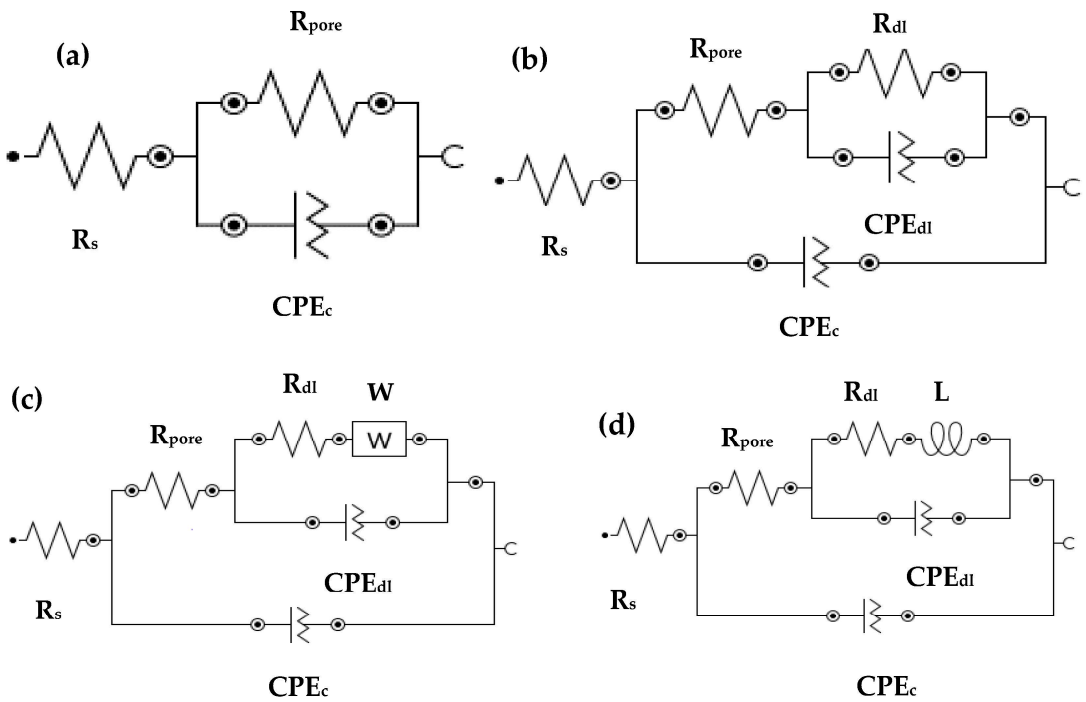

Figure 7. EEC for different coatings exposed in different $\mathrm{pH}$ solutions: (a) $\mathrm{pH} 6$ for sprayed, abraded, sealed, and plate; as well as pH 5 and 4 for sprayed and abraded; (b) pH 5 and 4 for sealed; (c) pH 5 for plate; and (d) $\mathrm{pH} 4$ for plate.

The electrochemical parameters of the samples are extracted from impedance plots in different $\mathrm{pH}$ solutions after fitting them in suitable EEC. This is shown in Table 3. In a pH 6 solution, the $R_{s}$ is almost the same as $R_{\text {pore }}$ owing to the low conductivity of the solution for sprayed and abraded samples. This $\mathrm{pH}$ solution is mildly acidic and did not affect the corrosion resistance properties of samples. The $R_{\text {pore }}$ for the sealed sample is much higher than for the plate and other samples. The lower $R_{\text {pore }}$ for the sprayed and abraded samples is due to the formation of more defects on the coating surface during the process of deposition, which facilitates the ingress of acidic ions. The samples tested in pH 5 exhibit the highest $R_{\text {pore }}$ and $R_{d l}$ values for sealed surface. From Table 3, it is observed that the $R_{s}$ value for the samples exposed to the $\mathrm{pH} 6$ and 5 solutions is the highest, decreased in $\mathrm{pH} 4$ owing to the highly acidic nature of solution. In the $\mathrm{pH} 4$ solution, more ions are involved, which increases the conductivity of the solution. Therefore, the $R_{S}$ is lower in a $\mathrm{pH} 4$ solution. The samples exposed to the $\mathrm{pH} 5$ solution exhibit the highest $R_{S}$ and $R_{\text {pore }}$ values among the other studied $\mathrm{pH}$ solutions. The higher $R_{S}$ and $R_{\text {pore }}$ of the samples in the $\mathrm{pH} 5$ solution might be owing to un-dissociated water molecules and the formation of a highly resistant passive film, respectively. It can be seen from Table 3 that the admittance $\left(Y_{01}\right.$ and $\left.Y_{02}\right)$ for the sealed and plate samples have minimum values, and the dispersion coefficient $\left(\alpha_{1}\right.$ and $\left.\alpha_{2}\right)$ is more evident in a pH 5 solution. The larger $\alpha$ (around 0.90 ) indicates that the surface has become more homogenized with a minimum amount of defects in the passive film. The presence of $\mathrm{W}$ in the $316 \mathrm{~L}$ stainless steel plate exposed to a $\mathrm{pH} 5$ solution indicates that the $\mathrm{Cr}^{3+}$ - and $\mathrm{Fe}^{3+}$-enriched ions diffuse from the inner and outer surfaces of the passive film. The sample exposed to the $\mathrm{pH} 4$ solution exhibited a lower $R_{\text {pore }}$ for the sprayed and abraded samples owing to the more acidic nature of the solution and the presence of more defects/pores on the top surface of the coating, which induces deterioration. The presence of inductance $(\mathrm{L})$ for the plate sample exposed to a $\mathrm{pH} 4$ solution is due to the partial breakdown of the passive film and an initial deterioration process. 
Table 3. Electrochemical parameters of coatings and plate in different acidic pH solutions are extracted after fitting of electrochemical impedance spectra in suitable EEC.

\begin{tabular}{|c|c|c|c|c|c|c|c|c|c|c|}
\hline \multirow{3}{*}{$\mathrm{pH}$} & \multirow{3}{*}{ Sample Details } & \multirow{3}{*}{$\begin{array}{c}R_{\mathrm{S}} \\
\mathrm{k} \Omega \cdot \mathrm{cm}^{2}\end{array}$} & \multicolumn{6}{|c|}{ Electrochemical Parameters } & \multirow{3}{*}{$\begin{array}{c}\text { W } \\
\left(1 \times 10^{-4}\right)\end{array}$} & \multirow{3}{*}{$\begin{array}{c}\mathrm{L} \\
\left(\mathrm{H} \cdot \mathrm{cm}^{2}\right)\end{array}$} \\
\hline & & & \multicolumn{3}{|c|}{$\mathrm{CPE}_{\mathrm{c}}$} & \multicolumn{3}{|c|}{$\mathrm{CPE}_{\mathrm{dl}}$} & & \\
\hline & & & $R_{\text {pore }} \mathrm{k} \Omega \cdot \mathrm{cm}^{2}$ & $Y_{o 1}\left(1 \times 10^{-4}\right)\left(\Omega \cdot \mathrm{cm}^{-2} \cdot \mathrm{s}^{-\mathrm{n}}\right)$ & $\alpha_{1}$ & $R_{d l} \mathrm{k} \Omega \cdot \mathrm{cm}^{2}$ & $Y_{o 2}\left(1 \times 10^{-6}\right)\left(\Omega \cdot \mathrm{cm}^{2} \cdot \mathrm{s}^{-0.5}\right)$ & $\alpha_{2}$ & & \\
\hline \multirow{5}{*}{6} & Sprayed & 1.32 & 1.47 & 7.94 & 0.74 & - & - & - & - & - \\
\hline & Abraded & 1.27 & 2.01 & 7.80 & 0.79 & - & - & - & - & - \\
\hline & Sealed & 1.09 & 607.00 & 0.01 & 0.94 & - & - & - & - & - \\
\hline & Plate & 1.02 & 69.42 & 1.45 & 0.83 & - & - & - & - & - \\
\hline & Sprayed & 1.37 & 1.97 & 1.54 & 0.95 & - & - & - & - & - \\
\hline \multirow{3}{*}{5} & Abraded & 2.18 & 4.37 & 0.01 & 0.95 & - & - & - & - & - \\
\hline & Sealed & 1.94 & 787.00 & 0.01 & 0.99 & 356.00 & 0.90 & 0.90 & - & - \\
\hline & Plate & 1.25 & 570.00 & 0.11 & 0.98 & 110.00 & 1.32 & 0.89 & 1.10 & - \\
\hline \multirow{4}{*}{4} & Sprayed & 0.35 & 0.37 & 22.69 & 0.70 & - & - & - & - & - \\
\hline & Abraded & 0.30 & 0.35 & 28.32 & 0.70 & - & - & - & - & - \\
\hline & Sealed & 0.55 & 563.00 & 0.21 & 0.90 & 173.00 & 1.10 & 0.89 & - & - \\
\hline & Plate & 0.32 & 103.00 & 0.21 & 0.89 & 88.00 & 1.19 & 0.88 & - & 25.63 \\
\hline
\end{tabular}




\subsubsection{Potentiodynamic Experiments for Different $\mathrm{pH}$ Solutions}

The potentiodynamic experiments on coatings and 316L stainless steel plate in different $\mathrm{pH}$ solutions are shown in Figures 8-10. The potentiodynamic experiments on coatings exposed to $\mathrm{pH} 6$ are shown in Figure 8. The sealed sample exhibits a lower current density than the plate, abraded, and sprayed surfaces. The corrosion potential $\left(E_{c o r r}\right)$ for the sealed surface shows higher activity than the stainless steel plate. This may be attributed to the reaction of the acidic solution with alkyl epoxide, which activated the surface.

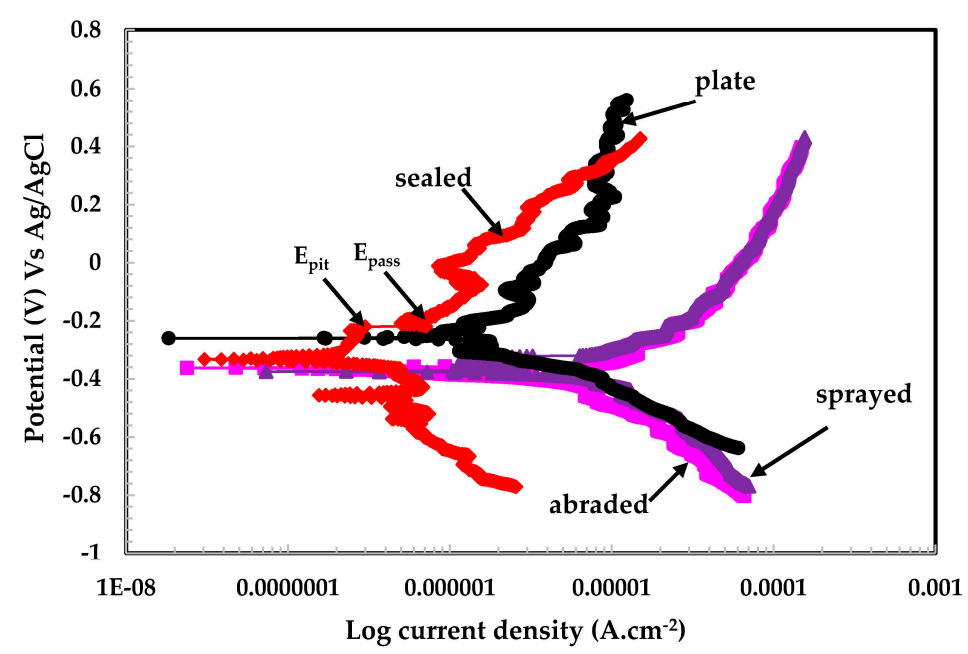

Figure 8. Potentiodynamic plots of 316L stainless steel coating applied by arc thermal spraying at $\mathrm{pH}=6$.

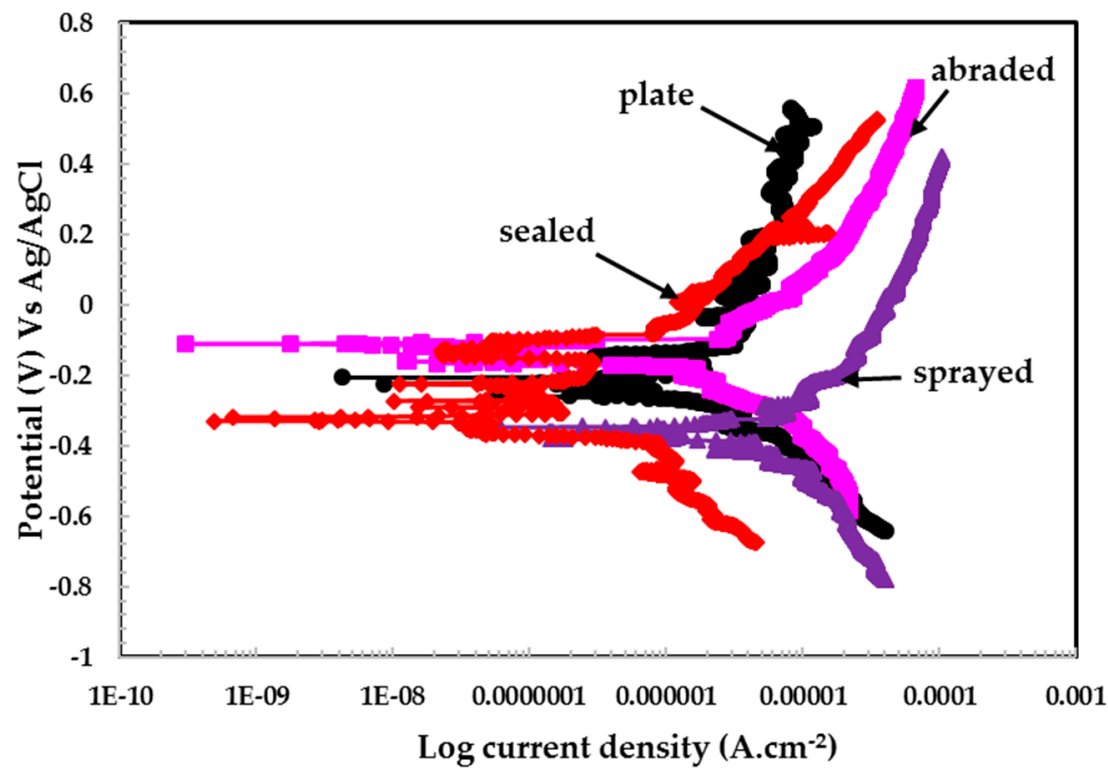

Figure 9. Potentiodynamic plots of 316L stainless steel coating applied by arc thermal spraying at $\mathrm{pH}=5$.

The sealed surface showed passive potential $\left(E_{\text {pass }}\right)$ and passive pitting potential $\left(E_{\text {pit }}\right)$, along with a decrease in current density, while other coatings did not show this type of behavior in the $\mathrm{pH} 6$ solution. It is observed that the plate surface exhibited higher anodic current than the sealed surface. The sprayed and abraded surfaces show a passive region, but the current density is higher than plate 
and sealed surfaces. The higher current density for the sprayed and abraded surfaces is due to the presence of more active sites (i.e., pores/defects) on the surface, which enhances the chemical reaction.

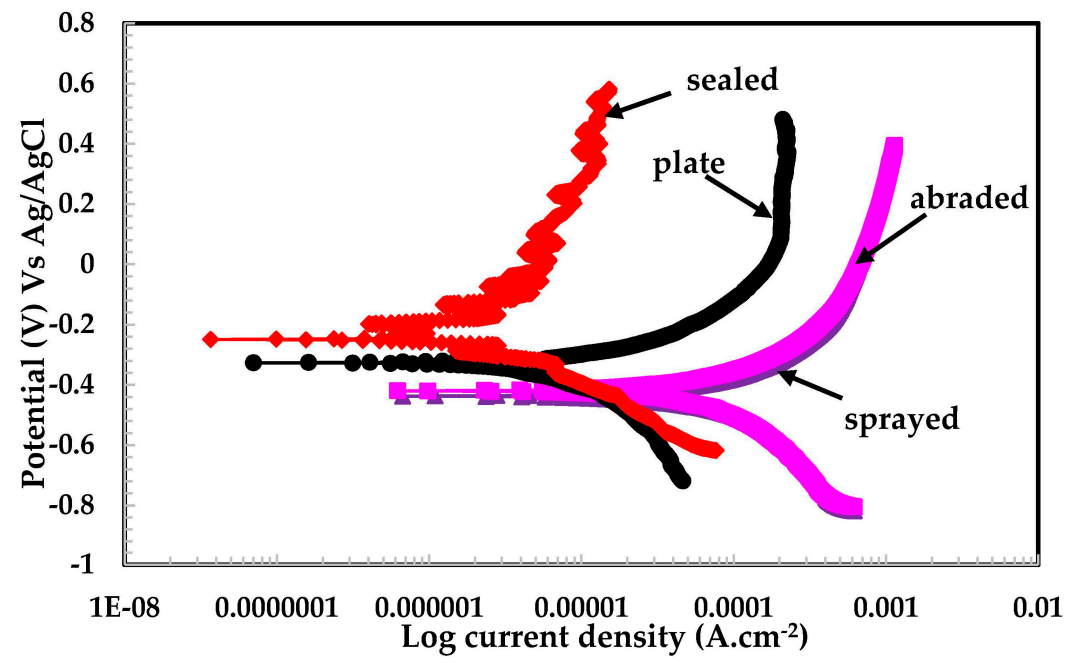

Figure 10. Potentiodynamic plots of 316L stainless steel coating applied by arc thermal spraying at $\mathrm{pH}=4$.

The plate, sprayed, and abraded surfaces show identical reduction properties for passive film during cathodic scanning, which indicates that the formation of the passive film exhibits the same characteristics in a $\mathrm{pH} 6$ solution. Therefore, the sprayed and abraded surfaces showing more anodic current density than the plate and sealed coatings can be attributed to reduced oxide films. However, the plate surface does not have any defects/pores on its surface. Therefore, it indicates that the plate surface contains more enhanced corrosion resistance than the sprayed and abraded surfaces. The scattered curve obtained for the $\mathrm{pH} 6$ solution may be due to the breaking and re-passivating of the film, especially in the case of the plate surface; on the sealed surface it is due to the presence micro-pores in the alkyl epoxide coating. This phenomenon occurs through all scanning ranges of potentiodynamic experiments.

From Figure 9, it can be seen that the samples exposed to the $\mathrm{pH} 5$ solution exhibited a high degree of protection. The sealed and plate surfaces show metastable potential, which may be due to the fact that the passive film was forming and breaking simultaneously during the scanning process. The sealed surface might contain very fine porous structures, by which the solution can penetrate below the alkyl epoxide to where stainless steel coating was applied.

This stainless steel coating reacts with aqueous $\mathrm{H}_{2} \mathrm{SO}_{4}$ in a $\mathrm{pH} 5$ solution and forms a passive layer. This layer is resistant to further attack from any aggressive ions on the surface. It is also observed from EIS plots (Figure 5) and Table 3 that sealed surfaces showed higher impedance than others because alkyl epoxide works as a barrier against the penetration of the solution. The stainless steel plate exhibited a greater pitting tendency than the other samples studied, which might be due to the presence of a defective passive film formed while breaking down simultaneously, forming a passive layer. This is a continuous process, therefore it has showed breakdown potential at different scanning ranges.

The sealed surface shows a greater breakdown potential in the $\mathrm{pH} 4$ solution than the other surfaces (Figure 10). The alkyl epoxide may be susceptible to an acid solution and cause dissolution resultant formation of meta-stable potentials. The sealed surface may be dissolved, or more defects/pits may form as a result of the chemical reaction of epoxide with the acidic solution.

The plate, abraded, and sprayed surfaces showed the formation of a passive film and corrosion products, deposited in the defects/pits of the coating surface. However, corrosion product enhances 
the passivation in a $\mathrm{pH} 4$ solution. The sealed surface shows nobler positive $E_{c o r r}$ and less corrosion current density $\left(I_{\text {corr }}\right)$ than other samples, which attributed high degree of protection.

An interesting observation was noted while analyzing the results of this experiment. After conducting potentiodynamic experiments on the sprayed and abraded samples, the solutions changed from having no color to yellow or green. This may be due to an increased dissolution rate of the stainless steel coating, resulting in the formation of iron hydroxide in a $\mathrm{pH} 4$ solution. This indicates that in this solution, the corrosion products again were deposited on the coating surface and formed a passive layer [35].

\section{Discussion}

Sulfur-reducing bacteria are present in waste water (sewer water), resulting in the reduction of $\mathrm{SO}_{4}{ }^{2-}$ into sulfur. Owing to the presence of sulfur, water can become acidic. To simulate this condition, $\mathrm{H}_{2} \mathrm{SO}_{4}$ was used in this study.

The conductivity of the solution ( $\mathrm{pH}$ 6) is low, but can be increased by adding salt. There was no salt or ion present beforehand, except for a few drops of $0.5 \mathrm{M}$ sulfuric acid in all of the solutions focused on in this study. The $\mathrm{pH}$ was reduced by adding a few drops of $0.5 \mathrm{M} \mathrm{H}_{2} \mathrm{SO}_{4}$, which is incapable of increasing the conductivity of the solution. The conductivity of distilled water is low-approximately $10 \times 10^{-6} \mathrm{~W}^{-1} \mathrm{~m}^{-1}(20 \mathrm{dS} / \mathrm{m})$. In all the other instances in this study, it was observed that the solution's resistance is high. In the presence of $\mathrm{H}_{2} \mathrm{SO}_{4}$, stainless steel forms a protective passive film that behaves like a semiconductor.

Banas and Stypula have observed that in aqueous $\mathrm{H}_{2} \mathrm{SO}_{4}$ acid solutions, austenitic steel is protected by the formation of an oxyhydroxide and oxide-hydroxide passive film due to un-dissociated water molecules in solution [30]. Lai et al. studied the characteristics of the formation of passive films on AISI 304 stainless steel in a $0.5 \mathrm{M} \mathrm{H}_{2} \mathrm{SO}_{4}$ solution and found that steel is composed of oxyhydroxides, $\mathrm{Fe}_{2} \mathrm{O}_{3}, \mathrm{FeO}, \mathrm{Cr}_{2} \mathrm{O}_{3}, \mathrm{NiO}$, sulfate, sulfite, and sulfide (FeS, NiS) [36]. The stability of passive films on stainless steel can vary, depending on the composition of alloys, environment, film thickness, and structure [37]. This passive film is partially hydrated; this was observed by Asami et al. [38].

There is a general agreement in the literature that the passive film of stainless steel in aqueous $\mathrm{H}_{2} \mathrm{SO}_{4}$ is due to the formation of $\mathrm{Cr}^{3+}$ compounds on the upper surface of the steel. This layer is of nanometer thickness and is enriched with chromium [39]. The thickness and composition of passive films can be altered by changing the $\mathrm{pH}$ and chloride content of the solution, and the composition of the steel. Elsener and Rossi have stated that when the $\mathrm{pH}$ of a solution is changed, it changes the tendency of the formation of passive films. As the $\mathrm{pH}$ was increased, the passive film became hydrated and more protective, as shown in this study [40].

The electrochemical parameters are extracted from potentiodynamic plots in different $\mathrm{pH}$ solutions by fitting the graph in a Tafel slope. The $R_{\text {pore }}$ and other parameters are presented in Figure 11 and Table 4 . In the $\mathrm{pH} 5$ solution, the polarization resistance of the passive film (Figure 11) for all studied samples was larger than in other $\mathrm{pH}$ solutions. This may be due to an increase in the film thickness, increased oxidation of iron, reduced $\mathrm{Cr}^{3+}$ [41], and un-dissociated water molecules [30]. Alhosseini and Vafaeian have reported that passive films in sulfuric acid behave as semiconductors and they found that AISI 304 and AISI 430 steel formed n- and p-type semiconductors, respectively [42]. As the $\mathrm{pH}$ is reduced, the $R_{\text {pore }}$ decreased dramatically. It is possible that the synergistic effect caused by the $\mathrm{pH} 4$ solution resulted in greater corrosion of the coating surface. 


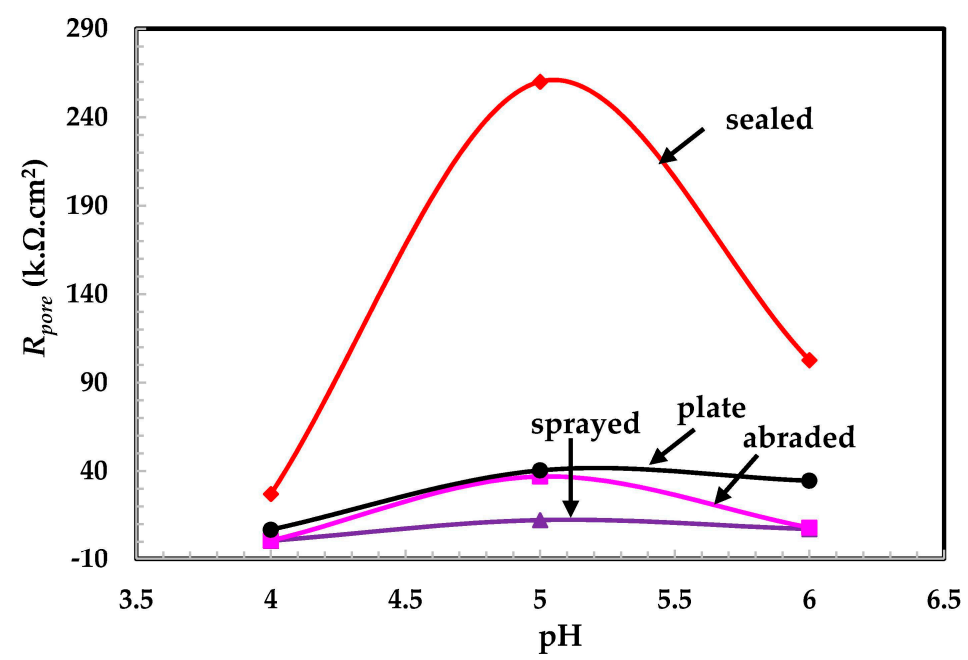

Figure 11. $\mathrm{pH}$ and $R_{\text {pore }}$ plots of coatings exposed to different $\mathrm{pH}$ solutions.

Table 4. Electrochemical parameters of coatings and plate are extracted from the Tafel region of potentiodynamic plots in different acidic $\mathrm{pH}$ solutions.

\begin{tabular}{|c|c|c|c|c|}
\hline \multirow{3}{*}{$\mathrm{pH}$} & \multirow{3}{*}{ Sample Details } & \multicolumn{2}{|c|}{ Electrochemical Parameters } & \multirow{3}{*}{ Corrosion Rate $\left(\mu \mathrm{m} \cdot\right.$ year $\left.^{-1}\right)$} \\
\hline & & $E_{\text {corr }}(\mathrm{V}) \mathrm{Vs} \mathrm{Ag} / \mathrm{AgCl}$ & $I_{c o r r}\left(\mu \mathrm{A} \cdot \mathrm{cm}^{-2}\right)$ & \\
\hline & & $($ Error, $\mathrm{V})$ & $\left(\right.$ Error, $\left.\mu \mathrm{A} \cdot \mathrm{cm}^{-2}\right)$ & \\
\hline \multirow[t]{4}{*}{6} & Sprayed & $-0.380(0.011)$ & $17.56(0.60)$ & 200.43 \\
\hline & Abraded & $-0.366(0.020)$ & $8.52(0.40)$ & 97.24 \\
\hline & Sealed & $-0.336(0.013)$ & $0.32(0.01)$ & 3.65 \\
\hline & Plate & $-0.244(0.012)$ & $1.56(0.07)$ & 17.80 \\
\hline \multirow[t]{4}{*}{5} & Sprayed & $-0.369(0.019)$ & $8.27(0.10)$ & 94.39 \\
\hline & Abraded & $-0.156(0.010)$ & $1.33(0.03)$ & 15.18 \\
\hline & Sealed & $-0.278(0.011)$ & $0.11(0.006)$ & 1.25 \\
\hline & Plate & $-0.219(0.011)$ & $0.74(0.02)$ & 8.44 \\
\hline \multirow[t]{4}{*}{4} & Sprayed & $-0.444(0.020)$ & $1124.5(20.50)$ & $12,834.76$ \\
\hline & Abraded & $-0.413(0.020)$ & $504.83(8.09)$ & 5762.00 \\
\hline & Sealed & $-0.255(0.015)$ & $3.31(0.15)$ & 37.77 \\
\hline & Plate & $-0.369(0.020)$ & $11.75(0.54)$ & 134.11 \\
\hline
\end{tabular}

It can be seen from Figure 11 that at a $\mathrm{pH}$ of 4 , the $R_{\text {pore }}$ values of the plate, abraded, and sprayed samples are almost the same. This indicates that the coating plays a significant role in protecting concrete against deterioration. This coating is more economical, while the stainless steel plate is very costly. In $\mathrm{pH} 5$, the $R_{\text {pore }}$ for abraded and plate surfaces are the same. This result indicates that this coating provides protection up to a certain extent of the acidic $\mathrm{pH}$ solution and works as effectively as the stainless steel plate coating. After the abrading of the sprayed surface, the pores/defects of the sprayed coating surface get filled, which reduces the active surface area and results in the formation of a more compact and uniform coating layer (Figure 3). Therefore, the abraded surface had a higher $R_{\text {pore }}$ value than the sprayed coating surface. The highest $R_{\text {pore }}$ was observed in the sealed surface for all studied $\mathrm{pH}$ solutions owing to the alkyl epoxide working as a barrier to the penetration of the acidic solution into the substrate.

Owing to the presence of more active sites on the sprayed sample, it exhibited more active (negative) potential for all of the tested $\mathrm{pH}$ solutions than the other samples (Table 4). It was observed that all of the coatings showed active potential in the $\mathrm{pH} 4$ solution, which may be due to the more acidic nature of the solution. The dissolution of the surface is enhanced in the $\mathrm{pH} 4$ solution, while at pH 6 it is decreased.

An interesting result was observed in the case of the $\mathrm{pH} 5$ solution: $E_{\text {corr }}$ values for all samples are nobler than other $\mathrm{pH}$ solutions. It might be that, in this solution, the surface became passive and 
resisted the solution's penetration into the coating surface. This result corroborates the finding of a corrosion current density $\left(I_{\text {corr }}\right)$ of coatings in the $\mathrm{pH} 5$ solution. The lowest $I_{\text {corr }}$ value is observed at $\mathrm{pH} 5$ for all studied coatings and may be due to the formation of a passive film that protects the surface. The corrosion rate $\left(\mu \mathrm{m} \cdot\right.$ year $\left.^{-1}\right)$ was calculated using the following equation [43]:

$$
\text { Corrosion rate }(\mu \mathrm{m} / \mathrm{y})=\frac{3.27 \times I_{\text {corr }} \times E . W .}{d}
$$

The corrosion rate in Equation (1) is expressed in micrometers per year $(\mu \mathrm{m} / \mathrm{y}) ; I_{\text {corr }}$ is in $\mu \mathrm{A} / \mathrm{cm}^{2}$. The $I_{\text {corr }}$ was obtained by dividing the total surface area of the working electrode by the corrosion current. E.W. represents equivalent weight $(\mathrm{g} / \mathrm{mole})$ and $\mathrm{d}$ is density $\left(\mathrm{g} / \mathrm{cm}^{3}\right)$.

The corrosion rate was the highest in the $\mathrm{pH} 4$ solution, which may have been caused by the aggressiveness of the solution. The sprayed coating showed the highest corrosion rate due to the dissolution of the coating and the penetration of the solution through the pores of the coating (Table 4). Therefore, the highest corrosion rate is observed in the $\mathrm{pH} 4$ solution. It is observed from the EIS and potentiodynamic plots that the coatings showed the highest corrosion resistance in the $\mathrm{pH} 5$ solution. The EIS results agree with electrochemical parameters extracted from potentiodynamic plots (Table 4). The error observed in $E_{\text {corr }}$ and $I_{\text {corr }}$ during the fitting of the potentiodynamic plots in the Tafel region is presented in Table 4 in brackets. A 5\% maximum error was observed during the fitting of the potentiodynamic curve for $E_{c o r r}$ and $I_{c o r r}$.

The protective mechanism of stainless steel coatings is described by the schematic presented in Figure 12. The outer surface of a water treatment reservoir is made of concrete embedded with reinforcement steel bars, which provides added strength to the overall structure.

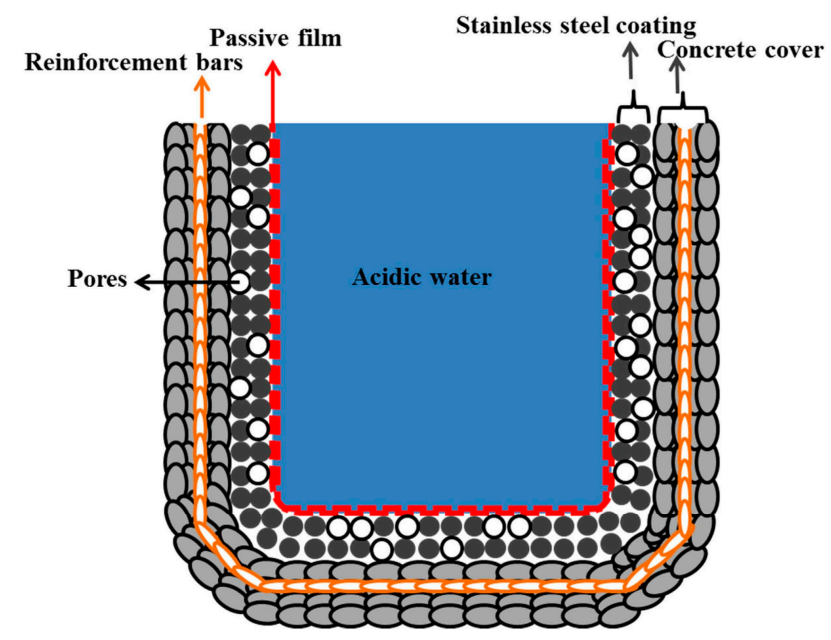

Figure 12. Schematic of the formation of a passive film on the stainless steel coated surface of a water treatment reservoir. The coating was applied by arc thermal spraying and the water is acidic in nature.

Waste/acidic water is stored in concrete reservoirs for purification and this contaminated water is purified by different processes. Therefore, the waste water affects the health of the concrete at longer durations of treatment. To protect the concrete from hazardous materials in waste water, a stainless steel coating was applied on the inner surface of the reservoir using the arc thermal spraying technique. This coating is porous in nature and, as a result, different techniques have been used to minimize the porosity of the coating.

Owing to the presence of hazardous chemicals in waste water, the $\mathrm{pH}$ of the water can reach acidic levels, comprising mostly sulfuric acids. To simulate this acidic environment, distilled water was acidified using $0.5 \mathrm{M} \mathrm{H}_{2} \mathrm{SO}_{4}$ acid. The stainless steel coating on the inner side of the reservoir reacted with the acidified water solution and formed a passive film, which provides further protection 
from corrosion. If a metallic coating other than stainless steel were used, it would be vulnerable to the acid solution and thus dissolve. This passive film can exist up to a mild acidic medium and below the critical $\mathrm{pH}$ level. The highly acidic $\mathrm{pH}$ solution destroys the passive film and causes deterioration.

\section{Conclusions}

Based on the above results and discussion, the following conclusions can be drawn:

1. The 316L stainless steel coating was applied to the concrete surface of a waste water reservoir, which provides protection across a variety of acidic $\mathrm{pH}$ solutions.

2. The alkyl epoxide sealed coating provided the best protection against contamination because it worked as a barrier against the penetration of acidic solutions.

3. The scattered impedance plots in the acidic $\mathrm{pH}$ solutions tested were due to the formation of capacitance and defective passive films at intermediate frequencies.

4. The different values of $\mathrm{pH}$ of the aqueous $\mathrm{H}_{2} \mathrm{SO}_{4}$ acid solution passivated the $316 \mathrm{~L}$ stainless steel coating because of the formation of $\mathrm{Cr}$-enriched phases on the top surface.

5. The lowest polarization resistance of the coatings in $\mathrm{pH} 4$ was because of the aggressiveness of the solution, which leads to the dissolution of the coating.

6. Defects in the surface of the coating made the coating susceptible to corrosion.

7. The presence of macro cells in the sprayed and abraded coatings resulted in the formation of pits and galvanic cells, which caused the coating to corrode in the acidic solution.

8. In the $\mathrm{pH} 5$ solution, the abraded coating exhibited almost the same $R_{\text {pore }}$ value as the $316 \mathrm{~L}$ stainless steel plate coating owing to the formation of a stable passive film. This passive film is formed in the presence of un-dissociated water molecules of the aqueous $\mathrm{H}_{2} \mathrm{SO}_{4}$ solution.

Acknowledgments: This research was supported by the Korea Ministry of Environment (MOE) through "Public Technology Program based on Environmental Policy (No. 2015000700002)" and basic science research program through the National Research Foundation (NRF) of Korea funded by the Ministry of Science, ICT and Future Planning (No. 2015R1A5A1037548).

Author Contributions: J.K.S. and J.H.P. conducted the experiments and wrote the initial draft of the manuscript. H.S.L. designed the experiments. J.K.S. and H.S.L. analyzed the data and wrote the final manuscript. H.S.L., M.A.I., and J.K.S. reviewed and contributed to the final revised manuscript. All authors contributed to the analysis of the data and read the final paper.

Conflicts of Interest: The authors declare no conflict of interest.

\section{References}

1. Giergiczny, Z.; Krol, A. Immobilization of heavy metals ( $\mathrm{Pb}, \mathrm{Cu}, \mathrm{Cr}, \mathrm{Zn}, \mathrm{Cd}, \mathrm{Mn})$ in the mineral additions containing concrete composites. J. Hazard. Mater. 2008, 160, 247-255. [CrossRef] [PubMed]

2. Lupsea, M.; Tiruta-Barna, L.; Schiopu, N. Leaching of hazardous substances from a composite construction product-An experimental and modelling approach for fibre-cement sheets. J. Hazard. Mater. 2014, 264, 236-245. [CrossRef] [PubMed]

3. Guo, Q. Increases of lead and chromium in drinking water from using cement-mortar-lined pipes: Initial modeling and assessment. J. Hazard. Mater. 1997, 56, 181-213. [CrossRef]

4. Jensen, H.S.; Lens, P.N.L.; Nielsen, J.L.; Bester, K.; Nielsen, A.; Haaning, H.-J.; Thorkild, V.J. Growth kinetics of hydrogen sulfide oxidizing bacteria in corroded concrete from sewers. J. Hazard. Mater. 2011, 189, 685-691. [CrossRef] [PubMed]

5. Owaki, E.; Okamoto, R.; Nagashio, D. Deterioration of concrete in an advanced water treatment plant. In Concrete under Severe Condition: Environment and Loading; Gjorv, E., Odd, E., Sakai, K., Banthia, N., Eds.; E \& FN Spon: London, UK; New York, NY, USA, 1998; p. 438.

6. Swamy, R.N.; Tanikawa, S. An external surface coating to protect the concrete and steel from aggressive environments. Mater. Struct. 1993, 26, 465-478. [CrossRef]

7. Vera, R.; Apablaza, J.; Carvajal, A.; Vera, M. Enrique, Effect of Surface Coatings in the Corrosion of Reinforced Concrete in Acid Environments. Int. J. Electrochem. Sci. 2013, 8, 11832-11846. 
8. Crowe, D.; Nixon, R. Corrosion of Stainless Steels in Waste Water Applications. Available online: http://www.hwea.org/wp-content/uploads/2015/07/150204_Corrosion_of_Stainless_Steels_in_ Wastewater_Applications.pdf (accessed on 19 January 2016).

9. Bhalerao, B.B.; Arceivala, S.J. Application of Corrosion Control Techniques in Municipal Water and Waste Water Engineering. Available online: http://eprints.nmlindia.org/5825/1/129--139.PDF (accessed on 9 January 2016).

10. Pawlowski, L. The Science and Engineering of Thermal Spray Coatings, 2nd ed.; John Wiley and Sons Ltd.: West Sussex, UK, 2008.

11. Jandin, G.; Liao, H.; Feng, Z.Q.; Coddet, C. Correlations between operating conditions, microstructure and mechanical properties of twin wire arc sprayed steel Coatings. Mater. Sci. Eng. A 2003, 349, 298-305. [CrossRef]

12. Chaliampalias, D.; Vourlias, G.; Pavlidou, E.; Stergioudis, G.; Skolianos, S.; Chrissafis, K. High temperature oxidation and corrosion in marine environments of thermal spray deposited coatings. Appl. Surf. Sci. 2008, 255, 3104-3111. [CrossRef]

13. Choe, H.-B.; Lee, H.-S.; Shin, J.-H. Experimental study on the electrochemical anti corrosion properties of steel structures applying the arc thermal metal spraying method. Materials 2014, 7, 7722-7736. [CrossRef]

14. Paredes, R.S.C.; Amico, S.C.; d'Oliveira, A.S.C.M. The effect of roughness and pre-heating of the substrate on the morphology of aluminium coatings deposited by thermal spraying. Surf. Coat. Technol. 2006, 200, 3049-3055. [CrossRef]

15. Lee, H.S.; Singh, J.K.; Ismail, M.A.; Bhattacharya, C. Corrosion resistance properties of Aluminum coating applied by arc thermal metal spray in SAE J2334 solution with exposure periods. Metals 2016, 6, 1-15. [CrossRef]

16. Guenbour, A.; Benbachir, A.; Kacemi, A. Evaluation of the corrosion performance of zinc-phosphate-painted carbon steel. Surf. Coat. Technol. 1999, 113, 36-43. [CrossRef]

17. Cinca, N.; Lima, C.R.C.; Guilemany, J.M. An overview of intermetallics research and application: Status of thermal spray coatings. J. Mater. Res. Technol. 2013, 2, 75-86. [CrossRef]

18. Bettridge, D.F.; Ubank, R.G. Quality control of high-temperature protective coatings. Mater. Sci. Technol. 1986, 2, 232-242. [CrossRef]

19. Steffens, H.D.; Babiak, Z.; Wewel, M. Recent developments in arc spraying. IEEE Trans. Plasma Sci. 1990, 18, 974-975. [CrossRef]

20. Muhamad, H.A.M.; Hayati, S.N.; Kiyai, A.S.; Binti, M.S.N. Critical process and performance parameter of thermal arc spray coatings. Int. J. Mater. Eng. Innov. 2014, 5, 12-27.

21. Davis, J.R. Surface Engineering for Corrosion and Wear Resistance; ASM International USA: Materials Park, $\mathrm{OH}$, USA, 2001.

22. Lee, H.S.; Singh, J.K.; Park, J.H. Pore blocking characteristics of corrosion products formed on Aluminum coating produced by arc thermal metal spray process in $3.5 \mathrm{wt} \% \mathrm{NaCl}$ solution. Constr. Build. Mater. 2016, 113, 905-916. [CrossRef]

23. Standard Test Method for Pull-Off Strength of Coatings Using Portable Adhesion Testers; ASTM D4541; STM International: West Conshohocken, PA, USA, 2010.

24. Maurice, V.; Yang, W.P.; Marcus, P. XPS and STM Study of Passive Films Formed on Fe-22Cr (110) Single-Crystal Surfaces. J. Electrochem. Soc. 1996, 143, 1182-1200. [CrossRef]

25. Goossens, A.; Macdonald, D.D. A photoelectrochemical impedance spectroscopic study of passive tungsten. J. Electroanal. Chem. 1993, 352, 65-81. [CrossRef]

26. Macdonald, D.D.; Sikora, E.; Engelhardt, G. Characterizing electrochemical systems in the frequency domain. Electrochim. Acta 1998, 43, 87-107. [CrossRef]

27. Song, H.; Macdonald, D.D. Photoelectrochemical Impedance Spectroscopy I. Validation of the Transfer Function by Kramers-Kronig Transformation. J. Electrochem. Soc. 1991, 138, 1408-1410. [CrossRef]

28. Ismail, K.M.; El-Moneim, A.A.; Badawy, W.A. Stability of Sputter-Deposited Amorphous Mn-Ta Alloys in Chloride-Free and Chloride-Containing $\mathrm{H}_{2} \mathrm{SO}_{4}$ Solutions. J. Electrochem. Soc. 2001, 148, C81-C87. [CrossRef]

29. Fattah-alhosseini, A.; Vafaeian, S. Passivation behavior of a ferritic stainless steel in concentrated alkaline solutions. J. Mater. Res. Technol. 2015, 4, 423-428. [CrossRef]

30. Banas, J.; Mazurkiewicz, B.; Stypula, B. Passivity of metals in concentrated and anhydrous solutions of sulphuric acid. Electrochim. Acta 1992, 37, 1069-1073. [CrossRef] 
31. Yadav, M.; Kumar, S. Experimental, thermodynamic and quantum chemical studies on adsorption and corrosion inhibition performance of synthesized pyridine derivatives on N80 steel in $\mathrm{HCl}$ solution. Surf. Interface Anal. 2014, 46, 254-268. [CrossRef]

32. Kumar, S.; Sharma, D.; Yadav, P.; Yadav, M. Experimental and quantum chemical studies on corrosion inhibition effect of synthesized organic on N80 steel in hydrochloric acid. Ind. Eng. Chem. Res. 2013, 52, 14019-14029. [CrossRef]

33. Boissy, C.; Alemany-Dumont, C.; Normand, B. EIS evaluation of steady-state characteristic of 316L stainless steel passive film grown in acidic solution. Electrochem. Commun. 2013, 26, 10-12. [CrossRef]

34. Singh, J.K.; Singh, D.D.N. The nature of rusts and corrosion characteristics of low alloy and plain carbon steels in three kinds of concrete pore solution with salinity and different pH. Corros. Sci. 2012, 56, 129-142. [CrossRef]

35. Singh, V.B.; Ray, M. Effect of $\mathrm{H}_{2} \mathrm{SO}_{4}$ addition on the corrosion behaviour of AISI 304 austenitic stainless steel in methanol-HCl solution. Int. J. Electrochem. Sci. 2007, 2, 329-340.

36. Lai, W.Y.; Zhao, W.Z.; Yin, Z.F.; Zhang, J. EIS and XPS studies on passive film of AISI 304 stainless steel in dilute sulfuric acid solution. Surf. Interface Anal. 2012, 44, 418-425. [CrossRef]

37. Marcus, P.; Olefjord, I. A round robin on combined electrochemical and AES/ESCA characterization of the passive films on Fe-Cr and Fe-Cr-Mo alloys. Corros. Sci. 1988, 28, 589-602. [CrossRef]

38. Asami, K.; Hosimoto, K.; Shimodaria, S. An XPS study of the passivity of a series of iron-chromium alloys in sulphuric acid. Corros. Sci. 1978, 18, 151-160. [CrossRef]

39. Olsson, C.O.A.; Landolt, D. Passive films on stainless steels-chemistry, structure and growth. Electrochem. Acta 2003, 48, 1093-1104. [CrossRef]

40. Elsener, B.; Rossi, A. Effect of $\mathrm{pH}$ on Electrochemical Behaviour and Passive Film Composition of Stainless Steels. Mater. Sci. Forum 1995, 192, 225-236. [CrossRef]

41. Mischler, S.; Vogel, A.; Mathieu, H.; Landolt, D. The chemical composition of the passive film on Fe-24Cr and Fe-24Cr-11Mo studied by AES, XPS and SIMS. Corros. Sci. 1991, 32, 925-944. [CrossRef]

42. Fattah-alhosseini, A.; Vafaeian, S. Effect of solution $\mathrm{pH}$ on the electrochemical behaviour of AISI304 austenitic and AISI 430 ferritic stainless steels in concentrated acidic media. Egypt. J. Pet. 2015, 24, 333-341. [CrossRef]

43. Dean, S.W. Electrochemical methods of corrosion testing. In Electrochemical Techniques for Corrosion; Baboian, R., Ed.; NACE: Houston, TX, USA, 1977; pp. 52-60.

(C) 2016 by the authors; licensee MDPI, Basel, Switzerland. This article is an open access article distributed under the terms and conditions of the Creative Commons Attribution (CC-BY) license (http://creativecommons.org/licenses/by/4.0/). 